\title{
Influence of Insulin Resistance and TSH on the Risk of Malignancy of Thyroid Nodule
}

\author{
Erdal SAYYIGIT ${ }^{1}$, Zafer PEKKOLAY ${ }^{*}$ and Alpaslan Kemal TUZCU² \\ ${ }^{1}$ Internal Medicine, Dicle University Medical Faculty, Turkey \\ ${ }^{2}$ Department of Adult Endocrinology and Metabolism, Dicle University Medical Faculty, Turkey
}

*Corresponding author: Zafer Pekkolay, Assist. Prof, MD, Department of Endocrinology and Metabolism, Dicle University Medical Faculty, Sur, Diyarbakır, Turkey, Tel: +90-412-2488001

\begin{abstract}
Objective: The incidence of thyroid cancer has increased in recent years. This increase may be due to the change of metabolic parameters in patients. This study was designed to clarify the association of malignancy of thyroid nodules with metabolic parameters.
\end{abstract}

\begin{abstract}
Materials and methods: This study designed as a cross-sectional study between January 2018 and May 2018. Samples were collected from the patients by thyroid fine needle biopsy and patients who had thyroid surgery. Group 1 patients were pathologically benign patients; Group 2 patients were pathologically malignant. In both groups, preoperative TSH, fasting insulin were measured and HOMA-IR calculated. Statistical analysis was performed.
\end{abstract}

Results: A total of 84 patients were included in the study. The benign group was 41 (F/M: 33/8) and the malignant group was 43 (F/M: 36/7). TSH levels $(1.44(0.0-9.4)$ versus $0.41(0.0-8.9) ; p<0.01)$, fasting insulin levels (13.0 (5.040.0) versus $9.4(3.2-25) ; p<0.05)$ and HOMA-IR levels (2.75 (1.06-13.19) versus $2.24(0.68-6.3) ; p<0.05)$ were significantly higher in the malignant group.

Conclusion: TSH elevation and insulin resistance may be associated with a risk of malignancyof thyroid nodule.

\section{Keywords}

Thyroid nodule, Metabolic parameter, Malignancy risk

\section{Introduction}

Thyroid cancer is the most common endocrine cancer [1]. The incidence of thyroid cancer has increased in recent years [2]. The solely reason for this increase cannot be explained by more frequent diagnostic procedures. This increase may be due to the change of metabolic parameters in patients. The association of malignancy potential of thyroid nodules with metabolic parameters has always been an interesting topic for scientists [3]. This situation is not fully elucidated. The incidence of thyroid cancer has increased with the increase of insulin resistance in recent years [4]. Studies have shown that excess insulin may play a role in the development of cancer due to mitogenic effects [5-7]. Rezzonico, et al. found that insulin resistance was higher in patients with differentiated thyroid cancer than in the control group, and those with normal weight and insulin resistance were more likely to have differentiated thyroid cancer [8].

TSH is the stimulus of thyroid cells. TSH accelerates cancer formation by making hypertrophy and hyperplasia in thyroid follicle cells. TSH elevation in patients with thyroid nodules is considered to be a risk factor for cancer of the nodule. In patients with differentiated thyroid cancer, TSH suppression is performed to prevent tumor growth. Studies suggest that there may be a positive relationship between TSH elevation and thyroid cancer $[9,10]$.

Our study was designed to clarify the association of malignancy of thyroid nodules with metabolic parameters.

\section{Materials and Methods}

\section{Patient selection}

This study was conducted a cross-sectional study between January 2018 and May 2018. Patients who had

Citation: SAYYIGIT E, PEKKOLAY Z, TUZCU AK (2018) Influence of Insulin Resistance and TSH on the Risk of Malignancy of Thyroid Nodule. Int Arch Endocrinol Clin Res 4:014. doi.org/10.23937/2572407X.1510014

Accepted: October 10, 2018: Published: October 12, 2018

Copyright: (C) 2018 SAYYiGiT E, et al. This is an open-access article distributed under the terms of the Creative Commons Attribution License, which permits unrestricted use, distribution, and reproduction in any medium, provided the original author and source are credited. 
Table 1: Patient characteristics/Endocrinological parameters of patients.

\begin{tabular}{|c|c|c|c|}
\hline & Group 1 (Benign) & Group 2 (Malignant) & $p$ value \\
\hline n & $41(49 \%)$ & $43(51 \%)$ & \\
\hline Female/Male & $\begin{array}{l}33 / 8 \\
(80.5 \%) /(19.5 \%)\end{array}$ & $\begin{array}{l}36 / 7 \\
(83.72 \%) /(16.28 \%)\end{array}$ & $>0.05$ \\
\hline Mean age (year) & $40.49 \pm 10.84$ & $39.79 \pm 11.23$ & $>0.05$ \\
\hline TSH ( $\mu \mathrm{lU} / \mathrm{mL})$ & & & \\
\hline Median (minimum-maximum) & $0.41(0.0-8.9)$ & $1.44(0.0-9.4)$ & $p<0.01$ \\
\hline Insulin ( $\mu \mathrm{lU} / \mathrm{mL})$ & & & \\
\hline Median (minimum-maximum) & $9.4(3.2-25)$ & $13.0(5.0-40.0)$ & $p<0.05$ \\
\hline HOMA-IR & & & \\
\hline Median (minimum-maximum) & $2.24(0.68-6.3)$ & $2.75(1.06-13.19)$ & $p<0.05$ \\
\hline
\end{tabular}

thyroid fine needle biopsy and total thyroidectomy due to thyroid nodule were included in the study. A total of 84 patients were included in the study. Patients were divided into two groups of patients whose age, sex, and body mass indexes were similar. Group 1 patients were pathologically benign patients $(n=41)$; Group 2 patients were pathologically malignant $(n=43)$.

\section{Inclusion criteria}

18-65 years of age, euthyroid patients, patients with at least $1>1 \mathrm{~cm}$ thyroid nodules and patients undergoing surgery.

\section{Exclusion criteria}

Pregnancy, non-euthyroid patients, other malignancy, Diabetes Mellitus, chronic Inflammatory disease.

Pre-operative fasting insulin levels, TSH, HOMA-IR (fasting insulin $x$ fasting glucose/405 $\geq 2.7$ insulin resistance) were calculated for the patients.

The study was approved by the local ethics committee (Dicle University 2018/84).

All patients received an informed consent form before taking them to study.

\section{Statistical analysis}

Patient data were transferred to SPSS 22.0 program and statistical analysis was performed. Categorical and normal distribution was expressed as mean \pm Standard Deviation (SD). Since the data did not show normal distribution, non-parametric evaluation was performed. Mann-whitney u test was used for non-parametric data. Significance was assessed at $p<0.05$.

\section{Results}

A total of 84 patients (F/M: $69(82.1 \%) / 15(17.9 \%))$ were included in the study. The mean age was $40.13 \pm$ 10.81 (18-64), the benign group consisted of 41 patients (F/M: 33/8) and the malignant group consisted of 43 patients (F/M: $36 / 7)$. The mean age of the benign group was $40.49 \pm 10.84(18-64)$, the mean age of the malig- nant group was $39.79 \pm 11.23$ (18-64). There was no difference in the ratio of female to male and age between the two groups ( $p>0.05$ ). TSH level was significantly higher in the malignant group $1.44(0.0-9.4)$ than in the benign group $0.41(0.0-8.9)$ and was statistically significant $(p<0.01)$. Fasting insulin levels were significantly higher in the malignant group $13.0(5.0-40.0)$ than in the benign group $9.4(3.2-25)$ and statistically significant ( $p$ $<0.05)$. The HOMA-IR level was significantly higher in the malignant group 2.75 (1.06-13.19) than in the benign group $2.24(0.68-6.3)$ and was statistically significant $(p<0.05)$ (Table 1$)$.

Of 43 malignant patients, 41 (95.3\%) had papillary thyroid carcinoma and $2(4.7 \%)$ had follicular thyroid carcinoma.

\section{Discussion}

Thyroid cancer is the most common endocrine cancer [11]. Unchanged risk factors for thyroid cancers are age, sex, and genetic predisposition [12]. The incidence of thyroid cancer is increasing gradually [13]. The widespread use of ultrasonography does not reflect this increase alone [14]. The exact cause of this frequency is unknown.

We found a positive relationship between insulin levels and malignancy in our study. The fasting insulin level in malignant patients was higher and statistically significant.

Studies have shown that excess insulin may play a role in the development of thyroid cancer due to mitogenic effects. Bae, et al. found that a positive association between insulin levels, HOMA IR and papillary thyroid cancer prevalence [15].

Wang, et al. found that insulin resistance caused growth and progression of the nodule by angiogenesis and increased intranodal blood flow. This finding may suggest that insulin resistance may be related to the formation of new blood vessels [16].

The HOMAIR parameter, derived from insulin and 
glucose, was found to be higher in our study in malignant patients. In the study of Heidari, et al. they found that in patients with differentiated thyroid cancer, the frequency of insulin resistance was about three times higher than that of the control group, and a positive correlation was found between HOMA-IR and thyroid cancer [17].

If there is such a relationship between insulin resistance and thyroid cancer; can medications improve insulin resistance prevent thyroid cancer? it is necessary to clarify the hypothesis. In our literature review, a Korean community-based retrospective study conducted by Cho, et al. showed that in a meta-analysis of a total of 250,000 patients $(125,000$ metformin $/ 125,000$ controls) after 7.2 years of follow-up, less thyroid cancer developed in the metformin group [18].

Pitoia, et al. found a positive correlation between insulin resistance and recurrence of thyroid cancer [19].

TSH can induce cancer by stimulating thyroid cells. In our study, the mean TSH level was higher in malignant patients. This difference was statistically significant.

Boelaert, et al. indicated that the malignancy risk of thyroid nodule was associated with the high level of TSH [20].

Haymart, et al. reported that serum thyroid-stimulating hormone levels were higher in thyroid nodule patients, associated with differentiated thyroid carcinoma and advanced tumor stage risks [21].

Fiore, et al. analyzed biopsy results and TSH values of patients with thyroid nodule biopsy in a series of approximately 10,000 patients and found a positive correlation between TSH level and malignancy. Patients with TSH levels $<0.4 \mathrm{micro} \mathrm{U} / \mathrm{ml}$ were found to be in the benign group [22].

\section{Conclusion}

We found that TSH, Insulin and HOMA IR were higher in patients with thyroid cancer. TSH elevation, insulin resistance, increased HOMA IR may lead to thyroid cancer.

\section{References}

1. Davies L, Welch HG (2014) Current thyroid cancer trends in the United States. JAMA Otolaryngol Head Neck Surg 140: 317-322.

2. Cabanillas ME, McFadden DG, Durante C (2016) Thyroid cancer. Lancet 388: 2783-2795.

3. Chen Y, Zhu C, Chen Y, Wang N, Li Q, et al. (2018) The Association of Thyroid Nodules with Metabolic Status: A Cross-Sectional SPECT-China Study. Int J Endocrinol 2018: 6853617.

4. Malaguarnera R, Vella V, Nicolosi ML, Belfiore A (2017) Insulin Resistance: Any Role in the Changing Epidemiology of Thyroid Cancer? Front Endocrinol (Lausanne) 8: 314.

5. Gallagher EJ, LeRoith D (2010) The proliferating role of insulin and insulin-like growth factors in cancer. Trends Endocrinol Metab 21: 610-618.
6. Tsatsoulis A (2018) The Role of Insulin Resistance/Hyperinsulinism on the Rising Trend of Thyroid and Adrenal Nodular Disease in the Current Environment. J Clin Med 7: 37.

7. Wang $X$, Häring M-F, Rathjen T, Lockhart SM, Sørensen D, et al. (2017) Insulin Resistance in Vascular Endothelial Cells Promotes Intestinal Tumor Formation. Oncogene 36: 4987-4996.

8. Rezzónico JN, Rezzónico M, Pusiol E, Pitoia F, Niepomniszcze H (2009) Increased prevalence of insulin resistance in patients with differentiated thyroid carcinoma. Metab Syndr Relat Disord 7: 375-380.

9. Moeller LC, Fuhrer D (2013) Thyroid hormone, thyroid hormone receptors, and cancer: a clinical perspective. Endocr Relat Cancer 20: 19-29.

10. McLeod DS, Watters KF, Carpenter AD, Ladenson PW, Cooper DS, et al. (2012) Thyrotropin and thyroid cancer diagnosis: a systematic review and dose-response meta-analysis. J Clin Endocrinol Metab 97: 2682-2692.

11. Pacini $F$, Schlumberger $M$, Dralle $H$, Elisei $R$, Smit JW, et al. (2006) European consensus for the management of patients with differentiated thyroid carcinoma of the follicular epithelium. Eur J Endocrinol 154: 787-803.

12. Iribarren C, Haselkorn T, Tekawa IS, Friedman GD (2001) Cohort study of thyroid cancer in a San Francisco Bay area population. Int J Cancer 93: 745-750.

13. Yu GP, Li JC, Branovan D, McCormick S, Schantz SP (2010) Thyroid Cancer Incidence and Survival in the National Cancer Institute Surveillance, Epidemiology, and End Results Race/Ethnicity Groups. Thyroid 20: 465-473.

14. Kitahara CM, Sosa JA (2016) The changing incidence of thyroid cancer. Nat Rev Endocrinol 12: 646-653.

15. Bae MJ, Kim SS, Kim WJ, Yi YS, Jeon YK, et al. (2016) High prevalence of papillary thyroid cancer in Korean women with insulin resistance. Head Neck 38: 66-71.

16. Wang K, Yang Y, Wu Y, Chen J, Zhang D, et al. (2015) The association between insulin resistance and vascularization of thyroid nodules. J Clin Endocrinol Metab 100: 184-192.

17. Heidari Z, Abdani M, Mansournia MA (2017) Insulin Resistance Associated With Differentiated Thyroid Carcinoma: Penalized Conditional Logistic Regression Analysis of a Matched Case-Control Study Data. Int J Endocrinol Metab 16: 14545.

18. Cho YY, Kang MJ, Kim SK, Jung JH, Hahm JR, et al. (2018) Protective Effect of Metformin Against Thyroid CancerDevelopment: A Population-Based Study in Korea. Thyroid 28: 864-870.

19. Pitoia F, Abelleira E, Bueno F, Urciuoli C, Schmidt A, et al. (2015) Insulin resistance is another factor that increases the risk of recurrence in patients with thyroid cancer. Endocrine 48: 894-901.

20. Boelaert K, Horacek J, Holder RL, Watkinson JC, Sheppard MC, et al. (2006) Serum thyrotropin concentration as a novel predictor of malignancy in thyroid nodules investigated by fine-needle aspiration. J Clin Endocrinol Metab 91: 4295-4301.

21. Haymart MR, Repplinger DJ, Leverson GE, Elson DF, Sippel RS, et al. (2008) Higher serum thyroid stimulating hormone level in thyroid nodule patients is associated with greater risks of differentiated thyroid cancer and advanced tumor stage. J Clin Endocrinol Metab 93: 809-814.

22. Fiore E, Rago T, Provenzale MA, Scutari M, Ugolini C, et al. (2009) Lower levels of TSH are associated with a lower risk of papillary thyroid cancer in patients with thyroid nodular disease: thyroid autonomy may play a protective role. Endocr Relat Cancer 16: 1251-1260. 